Supporting Information for

\title{
A Dual Fluorescence and NMR Study for the Interaction Between Xanthene Dyes and Nanoparticles
}

\author{
Hui Xu and Leah Beck Casabianca \\ Department of Chemistry \\ Clemson University, Clemson, SC 29634 USA
}

Table S1. Average and standard deviation of the maximum UV-Vis absorbance and fluorescence emission peak shift.

\begin{tabular}{|c|c|c|c|c|c|c|}
\hline $\begin{array}{c}\text { UV-vis } \\
\text { Absorbance }\end{array}$ & $\begin{array}{c}\text { peak shift } \\
(\mathbf{n m})\end{array}$ & $\begin{array}{c}\text { peak shift } \\
(\mathbf{n m})\end{array}$ & $\begin{array}{c}\text { peak shift } \\
(\mathbf{n m})\end{array}$ & $\begin{array}{c}\text { peak shift } \\
(\mathbf{n m})\end{array}$ & Average & STD \\
\hline RhB-CML NPs & 6 & 3 & 2 & 3 & 3.5 & 1.7 \\
\hline RhB-Amidine NPs & 2 & 1 & 0 & 0 & 0.75 & 0.95 \\
\hline
\end{tabular}

\begin{tabular}{|c|c|c|c|c|c|c|}
\hline Fluorescence & $\begin{array}{c}\text { peak shift } \\
(\mathbf{n m})\end{array}$ & $\begin{array}{c}\text { peak shift } \\
(\mathbf{n m})\end{array}$ & $\begin{array}{c}\text { peak shift } \\
(\mathbf{n m})\end{array}$ & $\begin{array}{c}\text { peak shift } \\
(\mathbf{n m})\end{array}$ & Average & STD \\
\hline RhB-CML NPs & 3 & 1 & 1 & 4 & 2.3 & 1.5 \\
\hline RhB-Amidine NPs & 0 & 0 & -1 & -1 & -0.5 & 0.57 \\
\hline
\end{tabular}

The UV-Vis and fluorescence experiments were repeated 4 times and the average and standard deviation of the peak shifts are shown in Table 1. The average absorbance peak shifts of $\lambda \max$ are $3.5 \pm 1.7 \mathrm{~nm}$ for RhB with CML NPs and are $0.75 \pm 0.95 \mathrm{~nm}$ for RhB with amidine NPs. The average fluorescence emission peak shifts are $2.3 \pm 1.5 \mathrm{~nm}$ for RhB with CML NPs and are -0.50 $\pm 0.57 \mathrm{~nm}$ for RhB with amidine NPs.

Table S2. NMR peak integral ratio between rhodamine B interacting with amidine and CML polystyrene latex beads and rhodamine $B$ alone.

\begin{tabular}{|c|c|c|c|c|c|c|c|}
\hline & Peak 1 & Peak 2 & Peak 3 & Peak 4 & Peak 5 & $\begin{array}{c}\text { Peak } \\
7,8\end{array}$ & Peak 9 \\
\hline$\frac{I_{R h B}-\text { Amidine }}{I_{R h B}}$ & 0.92 & 0.92 & 0.93 & 0.91 & 0.94 & 0.94 & 1.00 \\
\hline$\frac{I_{R h B-C M L}}{I_{R h B}}$ & 0.64 & 0.47 & 0.65 & 0.61 & 0.70 & 0.61 & 0.80 \\
\hline
\end{tabular}


Table S3. Average and standard deviation of the maximum STD effect of RhB with CML nanoparticles.

\begin{tabular}{|c|c|c|c|c|c|c|}
\hline $\begin{array}{c}\text { RhB peak } \\
\text { number }\end{array}$ & $\begin{array}{c}\text { STD effect } \\
(\max )\end{array}$ & $\begin{array}{c}\text { STD effect } \\
(\max )\end{array}$ & $\begin{array}{c}\text { STD effect } \\
(\mathrm{max})\end{array}$ & $\begin{array}{c}\text { STD effect } \\
(\mathrm{max})\end{array}$ & Average & $\begin{array}{c}\text { Standard } \\
\text { Deviation }\end{array}$ \\
\hline 1 & 0.22 & 0.26 & 0.24 & 0.29 & 0.25 & 0.03 \\
\hline 2 & 0.19 & 0.23 & 0.22 & 0.27 & 0.23 & 0.03 \\
\hline 3 & 0.22 & 0.27 & 0.25 & 0.30 & 0.26 & 0.03 \\
\hline 4 & 0.23 & 0.27 & 0.25 & 0.31 & 0.27 & 0.03 \\
\hline 5 & 0.27 & 0.31 & 0.29 & 0.34 & 0.30 & 0.03 \\
\hline 6 & 0.18 & 0.19 & 0.24 & 0.30 & 0.23 & 0.06 \\
\hline 7,8 & 0.31 & 0.35 & 0.33 & 0.38 & 0.34 & 0.03 \\
\hline 9 & 0.31 & 0.35 & 0.32 & 0.38 & 0.34 & 0.03 \\
\hline
\end{tabular}

Table S4. Average and standard deviation of the maximum STD effect of RhB with amidine nanoparticles.

\begin{tabular}{|c|c|c|c|c|c|c|}
\hline $\begin{array}{c}\text { RhB peak } \\
\text { number }\end{array}$ & $\begin{array}{c}\text { STD effect } \\
(\mathbf{m a x})\end{array}$ & $\begin{array}{c}\text { STD effect } \\
(\mathbf{m a x})\end{array}$ & $\begin{array}{c}\text { STD effect } \\
(\mathbf{m a x})\end{array}$ & $\begin{array}{c}\text { STD effect } \\
(\mathbf{m a x})\end{array}$ & Average & $\begin{array}{c}\text { Standard } \\
\text { Deviation }\end{array}$ \\
\hline 1 & 0.030 & 0.019 & 0.02 & 0.024 & 0.023 & 0.005 \\
\hline 2 & 0.019 & 0.012 & 0.013 & 0.015 & 0.015 & 0.003 \\
\hline 3 & 0.036 & 0.023 & 0.023 & 0.029 & 0.028 & 0.006 \\
\hline 4 & 0.032 & 0.02 & 0.021 & 0.025 & 0.025 & 0.005 \\
\hline 5 & 0.054 & 0.039 & 0.036 & 0.046 & 0.044 & 0.008 \\
\hline 6 & 0.042 & 0.03 & 0.031 & 0.039 & 0.036 & 0.006 \\
\hline 7,8 & 0.053 & 0.038 & 0.037 & 0.046 & 0.044 & 0.008 \\
\hline 9 & 0.067 & 0.049 & 0.05 & 0.061 & 0.057 & 0.009 \\
\hline
\end{tabular}



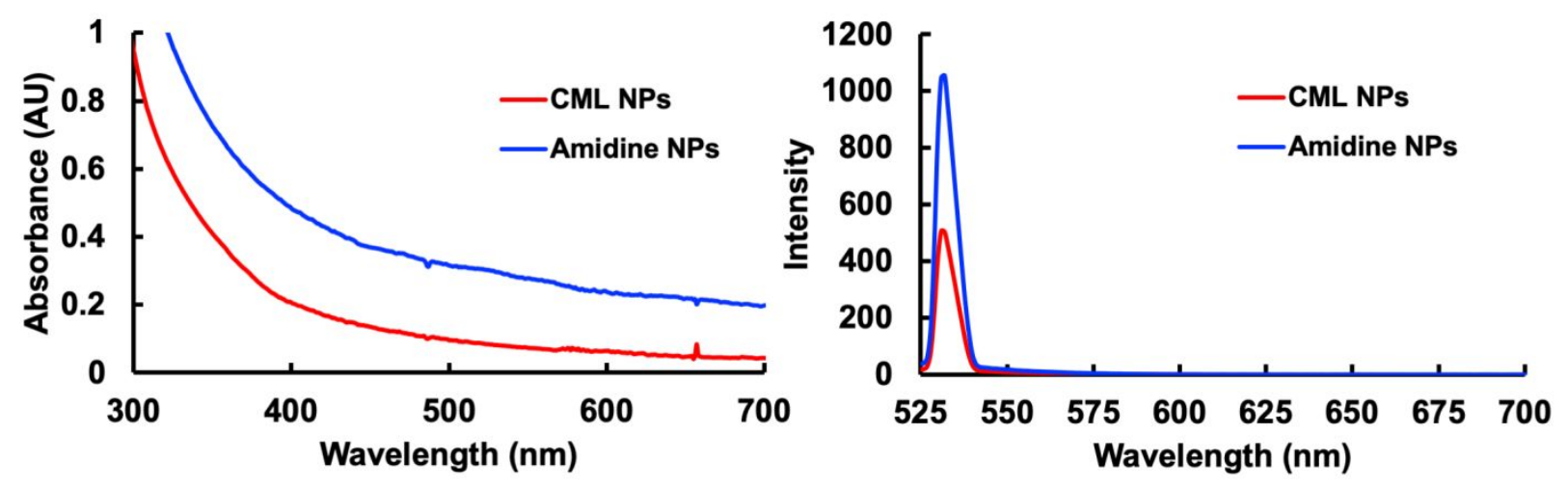

Figure S1. UV-Vis spectra (left) and fluorescence spectra (right) of CML polystyrene NPs and amidine polystyrene NPs in the absence of RhB.

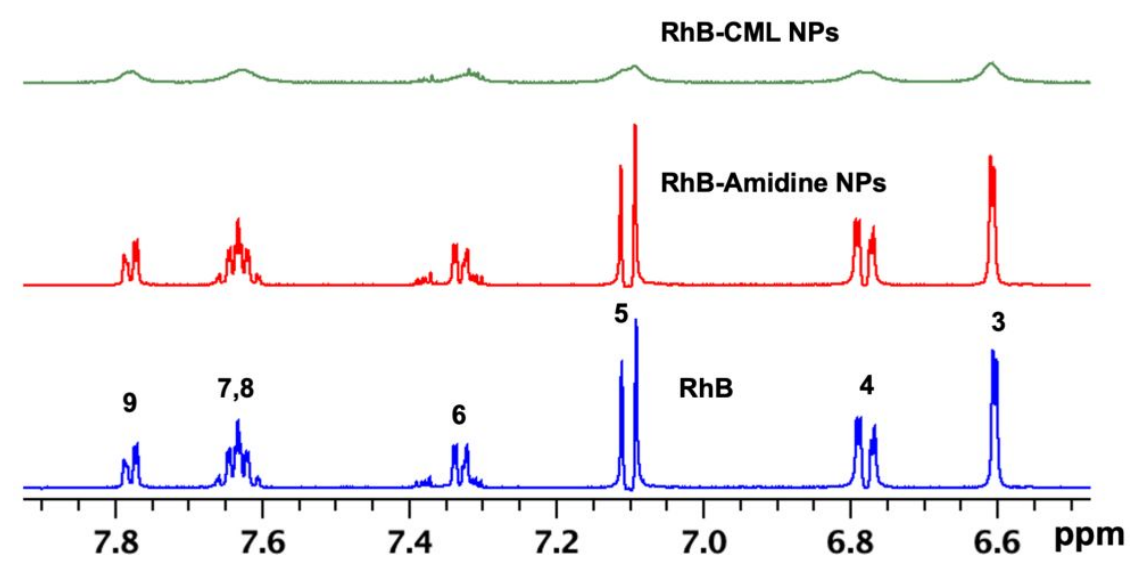

Figure S2. Expanded ${ }^{1} \mathrm{H}$ NMR spectrum between $6 \mathrm{ppm}$ and $8 \mathrm{ppm}$ of $1 \mathrm{mM}$ RhB, RhB-amidine NPs and RhB-CML NPs at $\mathrm{pH} 7$. 